\title{
CONFLITOS NO ESPAÇO URBANO:
}

\author{
um CaIs Mauá de TOdos?
}

\section{CONFLICTS IN THE URBAN SPACE:}

MAUÁ DoCKS FOR EVERYONE?

\author{
Clarice Misoczky de Oliveira ${ }^{\mathrm{A}, \mathrm{B}, \mathrm{e}, \mathrm{F}}$ \\ Universidade Federal do Rio Grande do Sul, \\ Programa de Pós-Graduação em Planejamento Urbano e Regional, Porto Alegre, Rio Grande do Sul, Brasil \\ Rafael Kruter Flores, , B, e, F \\ Universidade Federal do Rio Grande do Sul, \\ Programa de Pós-Graduação em Administração, Porto Alegre, Rio Grande do Sul, Brasil
}

R E S U M O : Neste artigo, buscamos compreender os conflitos no espaço urbano relacionados ao projeto de revitalização do Cais Mauá, em Porto Alegre. A pesquisa foi realizada por meio de consultas a documentos oficiais, reportagens de jornais, blogs e mídias sociais, bem como de observação não participante e participante de eventos públicos e reuniôes e de entrevistas. Argumentamos que os fatos recentes envolvendo a revitalização do Cais Mauá evidenciam que a produção social do espaço urbano resulta de processos contraditórios e conflituosos mais ou menos perceptíveis e que os eventos produzidos no tecido social, como manifestações de rechaço, mesmo que não impossibilitem o fluxo dos grandes acontecimentos, como os Grandes Projetos Urbanos, geram um efeito de desalienação e liberação de conflitos outrora latentes.

P A L A V R A S - C H A V E : espaço; lutas sociais; grandes projetos urbanos; movimentos sociais; planejamento urbano.

A B S T R A C T : The aim of this article is to understand the conflicts within the urban space related to the revitalization of the Maua Docks, in Porto Alegre, Brazil. Data was collected from official documents, newspapers, blogs, and social media, during participant and non-participant observations of public events and meetings, and interviews. We argue throughout the article that recent events involving the revitalization of the Maua Docks have demonstrated that the social production of urban space results from relatively perceptible contradictory and conflictive processes, and that events produced within the social fabric, such as demonstrations of rejection, while they do not prevent the flow of large-scale urban projects, they are nonetheless responsible for generating an effect of disalienation and demonstrating previously dormant conflicts.

K E Y W O R D S : space; social struggles; large urban projects; social movements; urban planning. 
Durante a realização da Copa das Confederaçôes, da Federação Internacional de Futebol (FIFA), em 2013, eclodiram, em todo o país, manifestaçôes contra os gastos excessivos do Estado, aprofundados por conta da realização de diversos megaeventos no país. Tais eventos podem ser entendidos como práticas de um "urbanismo mercadófilo" (SOUZA, 2002) e também como parte de estratégias de "empreendedorismo urbano" (HARVEY, 2006). Essas práticas e estratégias transformam o espaço urbano em mercadoria, ocasionando sérios prejuízos sociais às classes mais vulneráveis. As manifestações contrárias a essas práticas somaram-se às manifestaçôes que ficaram conhecidas como "Jornadas de Junho", que trouxeram à tona as práticas oligopolistas que organizam o transporte público no Brasil, além de terem reivindicado a defesa do direito à moradia digna e a melhores condiçôes de vida nas cidades brasileiras.

Porto Alegre, conhecida mundialmente pela experiência pioneira do Orçamento Participativo, poucos meses antes dos acontecimentos de junho de 2013, também foi palco de expressivas manifestaçôes. Em abril do mesmo ano, lideradas pelo movimento Bloco de Lutas, cerca de cinco mil pessoas foram às ruas contra o aumento da tarifa de ônibus na capital do Rio Grande do Sul (OLIVEIRA, 2013). A esses protestos, somaram-se lutas contra o corte de árvores para a duplicaçáo de avenidas e contra a expulsão de quase três mil famílias de baixa renda - alteraçóes destinadas a viabilizar obras da Copa do Mundo de 2014. Vale lembrar que, atrelado ao megaevento, a capital recebeu 18 Grandes Projetos Urbanos (GPUs), todos alinhados a estratégias de "empreendedorismo urbano" (HARVEY, 2006).

Este artigo busca compreender os conflitos no espaço urbano gerados a partir de um desses GPUs: a revitalização do Cais Mauá. Seguindo Lefebvre (1991), entendemos que o espaço é sempre produção social, resultado de processos que envolvem conflitos e contradiçóes. Alguns conflitos são subterrâneos, quase imperceptíveis, ocultados por ideologias e pela alienação que caracteriza a vida cotidiana (LEFEBVRE, 2014). Outros, no entanto, vêm à superfície em função das lutas sociais que com eles emergem, de sua própria natureza conflitiva ou de ambos os motivos.

A escolha desse GPU como objeto de estudo justifica-se pelo fato de que, no atual momento histórico, a revitalização do Cais Mauá revela claramente um processo de luta. Além disso, a análise desse objeto pode iluminar processos semelhantes que estáo ocorrendo em outras cidades brasileiras, como os casos do Cais José Estelita, em Recife, e do Porto Maravilha, no Rio de Janeiro. A pesquisa foi realizada por meio de consultas a documentos oficiais, reportagens de jornais, blogs e mídias sociais, bem como da observaçáo náo participante e participante de eventos públicos e reunióes de articulação. Também foi feita uma entrevista em profundidade com uma das lideranças do movimento Cais Mauá de Todos, no intuito de aprofundar o entendimento dos desdobramentos e açóes do movimento e de sua origem.

Argumentamos que os fatos recentes envolvendo a revitalização do Cais Mauá, em Porto Alegre, evidenciam que a produção social do espaço urbano resulta de processos contraditórios e conflituosos mais ou menos perceptíveis; ademais, demonstramos que os eventos produzidos no tecido social, como manifestaçóes de rechaço a determinados projetos, mesmo que não impossibilitem o fluxo de grandes acontecimentos como os GPUs, produzem um efeito de liberação de conflitos outrora latentes.

O texto é divido em três tópicos. Fazemos, inicialmente, uma consideração conceitual a respeito dos GPUs, tendo como referencial analítico as discussóes do 
francês Henri Lefebvre (1991; 2008a; 2008b; 2011; 2014). Em seguida, apresentamos o processo histórico de criação do projeto de revitalização do Cais Mauá, juntamente da contestaçáo social organizada por alguns atores principais. Finalmente, traçamos algumas considerações finais.

\section{OS GRANDES PROJETOS URBANOS E A PRODUÇÃO DO ESPAÇO}

A lógica concorrencial entre as cidades em busca de investimentos do setor financeiro se insere no contexto da crise do modelo fordista de produção nos países de capitalismo avançado. Tal crise tem como reflexo uma alteração no significado das cidades para a acumulação do capital. Segundo John Friedmann (1986), em The world city hypothesis, as cidades-chave tornam-se, no mundo globalizado, a base espacial de articulação e produção do capital global, o que influencia não só seu desenvolvimento econômico, mas também sua morfologia e infraestrutura.

Nesse sentido, no âmbito do planejamento urbano, novas ferramentas estáo sendo utilizadas para dar ancoragem territorial à ambição estratégica. Conforme Ingallina (2001), o projeto urbano traduz as orientaçóes de desenvolvimento econômico e social do projeto de cidade em suas manifestaçóes espaciais. O projeto urbano ocupa-se da dimensão formal, estética e funcional da cidade de acordo com sua ambição estratégica. Nesse contexto, o GPU pode configurar-se em um conjunto de pequenas intervençôes que resultam na execução de um projeto de cidade global. Para Lacroart e Palisse (2007), o GPU é o lugar de uma intervenção pública concentrada num espaço e tempo relativos, com a finalidade de desenvolver um pedaço da cidade por renovação, intensificação ou criação do zero.

$\mathrm{Na}$ França, os GPUs são vistos como uma ferramenta de planejamento urbano que trabalha a cidade de maneira holística, com intervençóes pontuais capazes de diluir seus efeitos no território como um todo. O planejamento por projetos, como é chamado, utiliza os GPUs de maneira concertada, viabilizando o desenvolvimento econômico e social sustentável das cidades.

Nos Estados Unidos, a origem do termo megaprojeto ${ }^{1}$ tem características dife-

1 Termo utilizado em países anglo-saxões para GPU. rentes, abrindo margem, por exemplo, para diversas operaçóes no espaço, que podem tratar desde grandes projetos monolíticos a grandes projetos de infraestrutura. Nessa concepção, o que muda é a forte participação do Estado. Para Altshuler e Luberoff (2003, p. 2),

[...] o termo megaprojeto denota iniciativas que são físicas, muito caras, e públicas. Mais especificamente, envolvem a criação de estruturas, equipamentos, preparação de locais para empreendimentos, ou a combinação de todos estes. Megaprojeto é, fundamentalmente, uma expressão da autoridade pública.

Entretanto, a partir dos anos 1990, com o processo de empresariamento da gestấo pública e o movimento do empreendedorismo urbano, as características dos megaprojetos se modificaram. Surgiram, assim, as concepçôes de parcerias público-privadas e outros tipos de intervençáo no espaço urbano, como a criação de centros esportivos, centros de convençôes, de cultura e lazer. 
No Brasil, o GPU tem ganhado destaque nas últimas décadas. São vários os projetos recentes que se enquadram nessa categoria: a Operação Faria Lima, em São Paulo; o Pelourinho, em Salvador; o Centro Dragão do Mar Arte e Cultura, em Fortaleza; o Ver-o-Peso e a Estação das Docas, em Belém do Pará; bem como os projetos associados à realização de megaeventos no país, como os projetos para os Jogos Pan-Americanos e as Olimpíadas, no Rio de Janeiro, e as obras da Copa do Mundo, em diversas cidades brasileiras ${ }^{2}$.

Harvey (2011) explica o investimento nesse tipo de projeto como uma busca por riqueza simbólica, tal como pode ser visto na gentrificação de determinadas áreas, na produçáo de comunidades, na reabilitação de paisagens urbanas e na recuperação da história valendo-se de imagens. O autor indica, ainda, que isso "nos ajuda a compreender o atual fascínio pelo embelezamento, pela decoração como códigos e símbolos de distinçấo social" (HARVEY, 2011, p. 82). A busca por arquitetos de grife e por projetos por ele denominados de arquitetura do espetáculo mostra a preocupação de governos locais em difundir a imagem da cidade e práticas relacionadas ao empreendedorismo urbano.

Harvey (2006) aponta, igualmente, uma preocupação com as rápidas mudanças no espaço urbano geradas por reaçôes inovadoras e competitivas através de alianças urbanas da classe dirigente, a partir das quais há a decorrência de uma série de incertezas e, por consequência, de instabilidade no sistema urbano. Essa instabilidade pode expressar-se de diversas maneiras, por exemplo, no crescimento da desigualdade social e no empobrecimento urbano verificados em cidades como Baltimore e Nova York. A destruição criativa do capitalismo se insere no espaço urbano, representada por um turbilhão de projetos inovadores de estádios, shoppings, renovação de waterfronts, centros culturais, entre outros, que estimulam a produção e o consumo da base urbana.

Dito isso, o projeto urbano é, então, compreendido como: (1) aplicação de um procedimento, levando em consideração os mecanismos de gestão e articulação público-privada; (2) um projeto político, além de uma configuração no espaço e no tempo; (3) um projeto que considera a escala dos impactos socioespaciais que ultrapassam seu entorno imediato; (4) algo que tem a marca da complexidade não só em razão da articulação de múltiplos atores, mas também da complexidade de usos. O GPU vai, portanto, muito além de sua dimensão arquitetônica. Trata-se de uma operação concertada entre múltiplos atores e com diversos impactos no espaço urbano e no desenvolvimento econômico e social da cidade.

Aqui, entendemos espaço urbano não como algo dado pelo ambiente físico. Como afirma Lefebvre (2008b), o espaço não é produto, não é objeto, não é mercadoria, não é simplesmente um instrumento. Para o autor, a problemática do espaço vivido, em oposição ao espaço "neutro", puramente epistemológico, é um aspecto essencial do conhecimento da realidade urbana. Em relação a essa questão, Lefebvre (2008b) explora diversas hipóteses. Na primeira, "o espaço é a forma pura", conceito que exclui a ideologia, a interpretação e o não saber. O espaço seria, nessa ótica, capaz de articular "o social e o mental, o teórico e o prático, o ideal e o real" (LEFEBVRE, 2008b, p. 41). Entretanto, tal hipótese implica a liquidação do tempo histórico, além de pesar sobre a cientificidade abstrata e o saber absoluto. Ela tem profunda relação com o urbanismo modernista e sua crítica: momento de valorização absoluta do saber científico, em que arquitetos e urbanistas acreditavam mudar o social através da forma. Lefebvre
2 Novais et al. (2007) expõem uma preocupação sobre a importação de projetos de natureza global com impactos adversos nas comunidades e na cidade. 
os chamou de "senhores do espaço". Ou seja, a forma concebida pelo técnico seria, depois, povoada pelos usuários, que se comportariam de acordo com o recipiente em que estivessem envoltos. Nesse sentido, essa noção exclui o espaço histórico e vivido.

Em outra hipótese, o espaço é social, um produto da sociedade, que resulta do trabalho e da divisão do trabalho, sendo, pois, o lugar geral dos objetos produzidos. O espaço é, então, uma objetivação do social. Confrontando tais formulações, Lefebvre (2008b, p. 44) conclui que o espaço não seria nem um ponto de partida nem um ponto de chegada, "mas um intermediário em todos os sentidos desse termo, ou seja, um modo e um instrumento, um meio e uma mediação". O espaço seria um instrumento político intencionalmente manipulado, em que um indivíduo ou um coletivo detém poder sobre ele, e o transforma conforme seus próprios objetivos. "Nessa hipótese, a representação do espaço sempre serviria a uma estratégia, sendo ao mesmo tempo abstrata e concreta, pensada e desejada, isto é, projetada" (LEFEBVRE, 2008b, p. 44). O espaço seria carregado de ideologia e saber técnico. As representaçóes do espaço seriam capazes de criar o consenso por meio de perspectivas, fossem elas verdadeiras ou falsas (LEFEBVRE, 1991). Em tal perspectiva, a detenção do saber da representação do espaço se transforma em poder de transformar ideias e sentimentos, ou seja, em poder de criar o consenso acerca do espaço. Essa dominaçáo racional-funcional vincula-se à reprodução da força de trabalho pelo consumo, sendo o espaço "o meio e o modo, ao mesmo tempo, de uma organização do consumo da sociedade neocapitalista" (LEFEBVRE, 2008b, p. 46).

Para Lefebvre (2008b, p. 46), "[...] as cidades seriam tâo somente unidades de consumo correlatas às grandes unidades de produção". A essa formulação se incorpora a teoria da falsa consciência, da burguesia, do alienado: o espaço instrumental se torna abstrato a partir de uma falsa representação de vocação estratégica, passando a ser "um lugar fora do tempo, da vida e da práxis". O espaço assume a forma de mercadoria, em que, "no limite [,] não há mais exatamente ideologia, mas somente a falsa consciência, com os discursos que ela engendra".

Entretanto, o autor alerta que essa hipótese serviria ao capitalismo concorrencial do século XIX, cujo enfoque recai na reprodução dos meios de produção - o capitalismo incorpora a "reprodução das relaçôes de produção" que se efetuam através da cotidianidade e dos momentos de lazer e cultura. Essa noção é complementar à última hipótese apresentada, mas leva a outra, mais complexa: "o espaço estaria essencialmente ligado à reprodução das relações (sociais) de produção” (LEFEBVRE, 2008b, p. 48). Seria o espaço da produção, ao mesmo tempo abstrato-concreto, homogêneo e desarticulado:

Essa reprodução se realiza através de um esquema relativo à sociedade existente, cujo caráter essencial é ser conjunta-disjunta, dissociada, mantendo uma unidade, a do poder, na fragmentação. Este espaço homogêneo-fraturado não é somente o espaço global do planejamento ou o espaço parcelar do arquiteto e dos promotores imobiliários, é também o espaço das obras de arte, por exemplo, o do mobiliário e do design. É o esteticismo que unifica os fragmentos funcionais de um espaço deslocado realizando, assim, seu caráter homogêneo e fraturado (LEFEBVRE, 2008b, p. 49).

Retomamos, nesse ponto, a já citada noção de Harvey (2011) sobre a sedução pelo embelezamento e dos símbolos de distinção social. Espaços homogêneos, com 
uma estética específica, criados em recortes, em partes fragmentadas no tecido urbano, tornam-se centros ou subcentros de consumo, polos de atração de uma determinada classe social, causando estranheza e constrangimento às demais classes e interferindo diretamente na noção de poder do espaço, assim como na dinâmica da estrutura urbana.

Segundo Lefebvre (2008b), tais centros de consumo dirigido e organizado - os lugares de lazer, de festa e tempo livre - mostram-se aparentemente dissociados da produção, embora estejam ligados ao trabalho produtivo. Baseado na fórmula trinitária de Marx ${ }^{3}$, o autor lança a hipótese do espaço conjunto-disjunto, situado entre a falsa consciência, a do alienado e a da ideologia, "que implica interpenetração do verdadeiro e do falso, e exclui a falsa consciência" (LEFEBVRE, 2008b, p. 52). Nas palavras do autor:

O espaço arquitetônico e urbanístico, enquanto espaço, tem essa dupla característica: desarticulado e até estilhaçado sob a coerência fictícia do olhar, espaços de coações e de normas disseminadas. Ele tem esse caráter paradoxal que se tenta definir aqui: junto e separado. É dessa maneira que ele é concomitantemente dominado (pela técnica) e não apropriado (para e pelo uso). Ele é imediato e mediato, ou seja, pertence a uma certa ordem próxima, a ordem da vizinhança, e a uma ordem distante, a sociedade, o Estado. A ordem próxima e a distante só tem uma coerência aparente que de modo algum impede a desarticulação (LEFEBVRE, 2008b, p. 53).

Em relação às ordens próxima e distante, Lefebvre (2001) qualifica a primeira delas como aquela de indivíduos mais ou menos organizados, de maneira mais ou menos ampla. Por sua vez, a segunda é caracterizada como aquela que se impóe; ela pode ser o próprio Estado ou qualquer organização e/ou instituição que detenha o poder. $\mathrm{Na}$ lógica em que os GPUs estão inseridos, a ordem distante se configura como, conforme Logan e Molotch (1993), uma "coalizão para crescer", formada por políticos, empresários, mídia e elites locais. Segundo Lefebvre (2001), através de seu poder de dominação, a ordem distante atua na ordem próxima, tornando-a um "co-ator":

Percebe-se que a burguesia, classe dominante, dispóe de um duplo poder sobre o espaço; primeiro, pela propriedade privada do solo, que se generaliza por todo o espaço, com exceçâo dos direitos das coletividades e do Estado. Em segundo lugar, pela globalidade, a saber, o conhecimento, a estratégia, a ação do próprio Estado. Existem conflitos inevitáveis entre estes dois aspectos, e notadamente entre o espaço abstrato (concebido ou conceitual, global e estratégico) e o espaço imediato, percebido, vivido, despedaçado, vendido. No plano institucional, essas contradiçóes aparecem entre os planos gerais de ordenamento e os projetos parciais de mercadores do espaço (LEFEBVRE, 2008b, p. 57).

Vislumbrando o espaço urbano, isto é, o urbano (a sociedade urbana) como um horizonte, como algo possível (LEFEBVRE, 2008a), o autor propõe o que denomina de "triplicidade do espaço": o espaço percebido (a prática do espaço), o concebido (a representação do espaço) e o vivido (os espaços de representação), sendo imprescindível que os três sejam analisados em conjunto pelo sujeito ou por determinado grupo social. Lefebvre ressalta a importância dos espaços públicos, aqueles sem o consumo organizado e direcionado, onde todos têm o direito de ir e vir, estar e permanecer, sem constrangimentos, onde tal triplicidade pode ser percebida sem interferências.
3 Trata-se da distinção das três dimensões da mercadoria, a partir da qual Karl Marx (1990) explica não apenas a dinâmica da produção, distribuição, troca e consumo, mas também a dinâmica do sistema capitalista como uma totalidade. Essas três dimensões são: o valor de uso, o valor de troca e o valor. 
Espaços onde a ordem próxima pode organizar-se por meio de feiras e festas, como faziam os camponeses na França (LEFEBVRE, 2014) quando levavam para os jardins sua produção e suas vivências, possibilitando que relaçôes se formassem e que fosse forjado um sentido de comunidade, de pertencimento ao espaço.

A análise dos GPUs como procedimento e projeto político, com base no referencial teórico de Lefebvre, permite-nos compreendê-los como uma dimensão ativa na produção social do espaço, estreitamente vinculada à forma mercadoria, à sociabilidade da sociedade burguesa. O processo que analisaremos no tópico seguinte se insere nessa perspectiva, tanto no que diz respeito ao projeto em si, quanto aos conflitos sociais que fazem parte de sua gênese e execução.

\section{CAIS MAUÁ DE TODOS?}

O GPU Cais Mauá é um projeto que visa a renovar uma parte desativada do porto de Porto Alegre. A ideia é transformar os $2,5 \mathrm{~km}$ de extensão do Cais em um local voltado para o comércio, serviços e turismo, com possibilidade de abrigar um shopping center e torres de escritórios. A fração do porto em questáo localiza-se no centro histórico da capital gaúcha, às margens do Rio Guaíba. O conjunto arquitetônico, construído no início do século XX, é composto por 11 armazéns, sendo que "o pórtico central e os armazéns $\mathrm{A}$ e $\mathrm{B}$ foram declarados patrimônio histórico nacional em 1983, e o restante do conjunto foi protegido pelo município em 11 de outubro de 1996, sob o no 46 do Livro Tombo" (CAIS, 2013). Trata-se de um local que possibilita uma vista privilegiada do pôr-do-sol no Rio Guaíba, conhecido cartão postal da cidade. Até recentemente, abrigava diversas atividades efêmeras de caráter público, como a Bienal do Mercosul, a Feira do Livro e a Feira Brasil Rural Contemporâneo, além de atividades permanentes, como a marina pública.

A vinculação desse GPU com a realizaçáo da Copa do Mundo 2014 foi exaltada pela Prefeitura Municipal de Porto Alegre (PMPA) como essencial. A revitalização do Cais Mauá, por exemplo, conforme notícia do Portal da PMPA, apareceu como uma das prioridades para a Copa de 2014: [...] o processo de revitalizaçâo do Cais Mauá está entre as principais preocupaçôes para a preparação de Porto Alegre para a Copa do Mundo de 2014, especialmente por representar uma profunda transformaçáo na área central da cidade (REVITALIZAÇÃO, 2008, grifos nossos).

Para a então governadora do Estado, Yeda Crusius, "o projeto pode ser considerado um dos maiores e mais revolucionários em revitalizaçáo urbana, seja pelo tamanho da área ou pelo impacto econômico e social que vai gerar" (FOGAÇA, 2009, grifos nossos). Já José Fortunati, o prefeito da cidade, em outro momento, afirmou que a "modernizaçáo sustentável do cais ir[ia] recuperar a relação da sociedade com o rio, promovendo intensa atividade cultural, econômica e turística na nossa Capital [...] e que a iniciativa eleva[va] para um novo patamar o processo de revitalizaçáo do Centro Histórico que a Prefeitura promove" (CONCESSIONÁRIA, 2011, grifos nossos).

A revitalização do Cais Mauá é um projeto antigo, que se iniciou em 1991 e passou por muitas administraçóes do município e do estado. A cada nova administração, novos estudos foram feitos. Depois de passar por várias versôes e realizaçóes de concursos públicos de projeto arquitetônico, em 2007, ano de confirmação da Copa 
do Mundo 2014 no Brasil, o projeto ganhou novos contornos. Na ocasiáo, a iniciativa privada foi convocada para participar da elaboraçáo do edital de Revitalização do Cais Mauá, a nova identidade do antigo projeto Porto dos Casais. A concorrência para a Solicitação de Manifestação de Interesse foi internacional. No ano seguinte, foi anunciado o consórcio vencedor, liderado pelo M. Sortti Business Consulting Group, do qual o arquiteto Jaime Lerner fez parte. O grupo apresentou um plano de negócios através de parceria público-privada (PPP) (CAIS, 2013).

O passo seguinte foi alterar o plano diretor para viabilizar o GPU, com projeto de lei encaminhado pelo prefeito Fortunati, definindo as regras de usos da área. A lei instituiu usos com apelo turístico, como centro de convençóes, centro de educação ambiental, museu de tecnologia, centro de referência de artesanato, espaço para incubadoras de empreendimento de base de tecnologia, e liberou a construção de edificaçóes com altura de até 100 metros em uma determinada área. Na ocasião da aprovação da lei, segundo uma das lideranças do Cais Mauá de Todos, já era possível identificar o comprometimento da PMPA e da grande maioria dos vereadores com o plano de negócios apresentado.

Uma vez legalizados os novos usos e concedidos índices construtivos atraentes para a construção civil, foi aberta a licitação para a empresa que ficaria responsável pela construção do projeto. Segundo as regras estabelecidas, a empresa poderia, inclusive, alterar o programa de necessidades proposto pela licitação anterior. A empresa vencedora, o Consórcio Cais Mauá, formado por um grupo espanhol, responsável pelo Port Vell, em Barcelona, e também integrado pelo arquiteto Jaime Lerner, obteve o direito de exploração da área por 25 anos.

Ainda em 2010, a Agência Nacional de Transportes Aquaviários (ANTAQ), órgáo ligado ao Ministério dos Transportes e que regula os portos do país, entrou com uma ação no Supremo Tribunal Federal (STF) para contestar o edital do cais, "[...] alegando que a área [era] propriedade da União, e não do Estado" (CAIS, 2013). Por fim, a ANTAQ realizou a desafetaçáo da área por meio de um Decreto da Presidência da República, sob a garantia de recebimento de $\mathrm{R}$ \$ 2,5 milhóes anuais pagos pelo arrendamento (CAIS, 2013).

O caso do GPU Cais Mauá é um exemplo das alianças formadas entre diferentes esferas de governo para a viabilizaçáo de um projeto. Nele, o articulador principal foi o governo estadual - o papel da PMPA tem sido o de incluir o novo negócio no plano diretor da cidade, tornando-o atrativo do ponto de vista da exploração pelo setor privado. Legalizado o projeto, a PMPA ficou responsável pelas aprovaçóes dos licenciamentos necessários para o início das obras. A necessidade de agilidade e flexibilidade nas aprovaçôes exigiu mudanças na estrutura organizacional da PMPA.

Em 2012, foi criado o Gabinete de Desenvolvimento e Assuntos Especiais (GADES), subordinado diretamente ao Gabinete do Prefeito, com a finalidade de ampliar a capacidade de investimentos no município por meio de parcerias público-privadas, viabilizando a execução de projetos especiais. O GADES se tornou o setor responsável pelos projetos de Revitalização do Cais Mauá e da Orla do Guaíbát. Nesse cenário, os técnicos da Secretaria de Planejamento Municipal (SPM) foram postos à parte do processo.

$\mathrm{Na}$ coalizão para a implantação de GPUs sob a ótica do empreendedorismo urbano, o Grupo RBS5 atuou com força. Em uma reportagem especial sobre o lançamento do projeto (Figura 1), afirma-se que o Cais Mauá “[...] será palco hoje de
40 projeto de revitalização da orla do Guaíba abrange área com extensão de $6 \mathrm{~km}$. Ele foi elaborado pelo escritório do arquiteto Jaime Lerner, contratado pela prefeitura sem licitação ou concurso público, o que tem sido alvo de críticas por vários segmentos da sociedade.

5 O Grupo Rede Brasil Sul (RBS) é um dos maiores conglomerados de empresas do ramo de comunicação do país. 
6 A Defesa Pública da Alegria "busca a defesa das manifestações públicas, sociais e artística; repúdio às políticas de remoção das famílias e comunidades atingidas pela Copa do Mundo FIFA e a especulação imobiliária, à privatização do espaço público e ao aumento das passagens de ônibus" (O QUE, 2012).

7 Um dos projetos da Vonpar é construir uma minifábrica da Coca-Cola dentro de um dos pavilhões do Cais.

8 Maiores informações disponíveis em: <https:// w w w. facebook.com/ ocupacaismaua?fref $=$ ts $>$. Acesso em: 15 jun. 2016.

9 Entre esses eventos, merece destaque a Serenata lluminada, em que a população é chamada a trazer seus instrumentos, velas, lanternas, comidas e bebidas para "fazer um encontro que mistura alegria, expressão e reflexão sobre o uso dos espaços públicos da nossa cidade" (SERENATA, 2014). uma espécie de renascimento da metrópole" (MELO, 2011, grifos nossos), acrescentando, em seguida: "ao meio-dia, o Governador Tarso Genro transfer[iu] a posse dos mais de 180 mil metros quadrados do Cais Mauá à iniciativa privada, o sonho de que aquele se torne um lugar realmente público começ[ou] a virar realidade" (MELO, 2011, grifos nossos). Observamos uma inversão de termos e uma retórica mistificadora. O local, que até entáo abrigava diversas atividades de caráter aberto e público, iria, segundo a matéria, tornar-se "um lugar verdadeiramente público" ao ser entregue para o setor privado, quando o que de fato ocorre é a privatização desse espaço.

Após a assinatura do termo, algumas medidas por parte do consórcio Cais Mauá foram tomadas, como a retirada do tradicional barco de passeio no Rio Guaíba, do Cisne Branco, da Marina Pública e o fim da realizaçáo de eventos como a tradicional Feira do Livro e a Bienal do Mercosul. Diante desse cenário e de outras transformaçóes em andamento por ocasião da Copa do Mundo de 2014, o Movimento em Defesa Pública da Alegria ${ }^{6}$ conduziu uma série de açóes na área do Cais Mauá e arredores do Centro Histórico. Com a promoção de shows e apresentaçôes artísticas, o grupo denunciou a privatização de espaços públicos como o Cais Mauá e o Largo Glênio Peres. Este último recebeu investimentos para reforma do Grupo Vonpar, representante da Coca-Cola no estado, e, desde então, passaram a ser proibidas manifestaçôes artísticas e/ou políticas no local. Aos finais de semana, esse espaço, um tradicional ponto de circulação de pedestres no coração do centro da cidade, dá lugar a um estacionamento. Devido às reincidentes manifestaçôes contra a presença da marca Coca-Cola no Largo, aos atrasos das obras do Cais Mauá e à especulação sobre falta de idoneidade das empresas formadoras do consórcio, o Grupo Vonpar se retirou como investidor do GPU?

Após a Copa do Mundo de 2014, passou o sentimento de bem-estar associado aos jogos (MAENNIG, 2009). Seguindo a linha dos movimentos Ocuppy, as açôes do Movimento em Defesa Pública da Alegria deram origem a outro movimento, o Ocupa Cais Mauá ${ }^{8}$, que, além de festas, promove eventos envolvendo manifestaçôes artísticas e culturais?.

O Ocupa Cais Mauá, liderado por personalidades da cena cultural/noturna porto-alegrense, articulou-se ao Movimento Ocupa Estelita através de uma de suas líderes, a advogada e professora universitária Liana Cirne Lins, a qual começou a participar dos eventos do grupo e também a assessorá-lo, fundamentando-se na experiência de oposição ao GPU Cais José Estelita, em Recife.

Em uma carta aberta datada de 2014, o Ocupa Cais Mauá expôe seu posicionamento frente ao GPU. Nela, o movimento repudia

[...] a falta de diálogo e de transparência, o desprezo pelo interesse público, o descaso com a memória e com o patrimônio histórico da cidade, o desrespeito com o meio ambiente, entre outras violaçôes que não condizem com uma sociedade democrática. Nós, enquanto movimentos organizados da sociedade civil, nos opomos frontalmente a esse modelo autoritário de revitalização urbana, com a mesma veemência que combatemos qualquer forma de abandono ou subutilização do nosso Cais Mauá. Acreditamos que este processo deve considerar as vozes que vêm de diferentes regióes da cidade e deve ser construído sobre princípios como diversidade, inclusão, bem como valorizaçấo e respeito ao patrimônio histórico, cultural, social e ambiental. Entendemos que a cidade não pode ser 
tratada como mercadoria, e sim como espaço compartilhado de interação, apoio mútuo e fortalecimento dos que nela habitam (CARTA, 2014).

Observamos que o movimento, embora se posicione contra a cidade compreendida como mercadoria e aos usos que estão sendo destinados à área, acredita que um projeto baseado na participação e discussão com a sociedade civil e com a participação do setor privado pode ser uma alternativa favorável.

Entre o final de 2014 e o início de 2015, o processo de implementação do GPU e o movimento Ocupa Cais Mauá ganharam novos contornos. O grupo espanhol saiu do Consórcio Cais Mauá, e Jaime Lerner passou a ser o arquiteto responsável. Um novo consórcio foi criado, o Consórcio Viva Cais Mauá. O projeto arquitetônico não possuía liberação da PMPA para a sua execução até o momento em que este artigo foi escrito. Nessa nova fase, o projeto foi divido em três setores. No setor Usina do Gasômetro, haverá um shopping, com $35.000 \mathrm{~m}^{2}$ de lojas e $60.000 \mathrm{~m}^{2}$ voltados para 2.160 vagas de automóveis. O setor Armazéns será composto por uma área de 24.000 $\mathrm{m}^{2}$ destinados a lojas, restaurantes e a um museu sobre a história de Porto Alegre. Por fim, no setor Docas haverá uma praça, três torres comerciais de aproximadamente $60.000 \mathrm{~m}^{2}$ e $39.000 \mathrm{~m}^{2}$ de estacionamento para 1.500 vagas.

O novo consórcio, frente às ações realizadas pelo Ocupa Cais Mauá, fechou os portóes do cais para o acesso público, impedindo novos eventos. Como estratégia, o movimento preferiu não realizar invasões ou promover embates com os seguranças do consórcio. Sem poder ocupar a área, deu-se origem a um novo movimento, composto pelos atores anteriores e também por novas personalidades e instituiçóes. Foi criado, assim, o Cais Mauá de Todos ${ }^{10}$.

Segundo um dos líderes entrevistados, a estratégia de não ocupar o Cais Mauá se deu por acreditar que a ação teria pouca visibilidade, uma vez que existe um muro que separa o cais da cidade. Além disso, esse muro, em caso de confronto com a polícia, dificultaria a dispersão. A organização do movimento também ganhou novos contornos, incorporando três esferas de ação: comunicação, política e jurídica.

O movimento optou, assim, por seguir a estratégia de ocupação dos espaços adjacentes ao cais por meio de encontros artísticos de caráter festivo. Nessa nova fase de contestação, os shows deixaram de ser colaborativos, contando com bandas e músicos de destaque na cena cultural da cidade. Os eventos foram concentrados em dois lugares estratégicos: um, em frente ao pórtico central do Cais Mauá, e o outro, na Praça Brigadeiro Sampaio, localizada em uma das extremidades do empreendimento. A praça, de uso intenso por parte dos moradores do centro histórico, sofrerá forte impacto, em funçấo do corte de árvores e dos acessos ao empreendimento.

O Cais Mauá de Todos conta com o apoio de vários movimentos sociais, organizaçôes náo governamentais, entidades classistas, sindicatos etc. Entre eles, estão: Minha Porto Alegre; Instituto de Arquitetos do Brasil (IAB-RS); Sindicato dos Engenheiros (SENGE/RS); Defesa Civil do Patrimônio Histórico (Defender); Associação Gaúcha de Proteção ao Ambiente Natural (AGAPAN); Poa em Movimento; Núcleo de Ecojornalistas do Rio Grande do Sul (NEJ/RS); Defesa Pública da Alegria; Ocupa Cais Mauá; Porto Alegre Ativa; Associação Comunitária do Centro Histórico de Porto Alegre; Amigos da Rua Gonçalo de Carvalho; Associação pela Mobilidade Urbana em Bicicleta (Mobicidade); Laboratório de Políticas Públicas e Sociais (LAPPUS); Chega de Demolir Porto Alegre; Fast Food Cultural (DEFENSORES, 2015).
10 Mais informações disponíveis em: <https://www. facebook.com/caismauadetodos>. Acesso em: 15 jun. 2016. 
11 Mais informações disponíveis em: <https://drive. google.com/file/d/0B1d QaqdWsen3cUVDWWg-

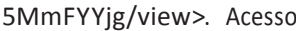
em: 15 jun. 2016.
Nos eventos, alternam-se shows com falas de pessoas conhecidas, como a citada Liana Cirne Lins, do Ocupa Estelita. Uma das falas tem sido a da arquiteta Maria Helena Cavalero, que concebeu um projeto alternativo ao Viva Cais Mauá. O projeto, desenvolvido em 2008 como trabalho final de graduação na Faculdade de Arquitetura da Universidade Federal do Rio Grande do Sul (FA/UFRGS), tem sido posto como uma, entre várias outras, forma de pensar outro espaço na área do cais ${ }^{11}$. Além disso, o movimento vem trabalhando a ideia de montar a Fundação Cais Mauá para se fortalecer, contando com o SENGE/RS para realizar um estudo de viabilidade econômica do projeto alternativo (HOFMEISTER, 2015). A ideia é ter um contraponto à especulação imobiliária por conta dos altíssimos investimentos que são ditos essenciais à revitalização da área.

O Cais Mauá de Todos, inspirado no Ocupa Estelita, tem também uma abordagem legalista, adotando como estratégia a alternativa de derrubar a lei que aprovou os novos parâmetros urbanísticos para a área, uma vez que uma das cláusulas foi descumprida pelo consórcio. Existe, ainda, a possibilidade de criar a chancela e o tombamento da paisagem, impossibilitando que o shopping center e as torres sejam construídas na área.

Percebemos, pois, uma mudança de discurso em relação ao grupo Ocupa Cais Mauá. Isso pode ser comprovado no seguinte trecho:

Obviamente que nós não queremos que aquela área continue abandonada e degradada. Nós queremos sim progresso e desenvolvimento, geração de empregos, tudo isso. Mas náo aceitamos shopping e torres naquela área da cidade. E queremos envolver a populaçáo nessa discussão (CAIS MAUÁ DE TODOS, 2015, p. 1).

O discurso é menos combativo e mais colaborativo. Não se trata de uma oposição ao sistema que propicia a criação do GPU, e sim do GPU em si, desconsiderando suas conexôes com uma totalidade social. Em nossa análise, entendemos que o movimento Cais Mauá de Todos reivindica a participação da sociedade na construção de um projeto, articula suas açóes em reunióes fechadas com atores selecionados. A participação de caráter aberto e público acontece apenas nos atos promovidos pelo movimento. Os manifestantes têm a preocupação de serem tachados de "vândalos e baderneiros", "os contra tudo" ou "os contra o progresso" - rótulos utilizados pelas autoridades locais e mídia nos últimos tempos, em meio às manifestaçôes de junho e julho de 2013, numa tentativa de desqualificar as lutas sociais. Deixam claro que não são contra o projeto e que querem participar. Embora se intitulem contra a cidade mercadoria, eles náo se posicionam claramente quanto ao uso elitista ao qual o projeto é destinado.

Podemos compreender melhor essa posição do movimento e da mídia local dominante a partir do conteúdo de uma carta aberta do Cais Mauá de Todos publicada em resposta a um artigo do jornal do Grupo RBS, filiado à Rede Globo. O artigo foi elaborado por Rosane Oliveira, comentarista política da emissora, um dia após a primeira audiência pública sobre os trâmites legais para a aprovação do Estudo de Impacto Ambiental pela PMPA. A audiência foi marcada pela resistência da população quanto à construção das torres de negócios, dos estacionamentos e do shopping center. A PMPA e, principalmente, os empreendedores mostraram-se fechados a qualquer tipo de diálogo. 
Segundo Rosane de Oliveira, no Rio Grande do Sul, "qualquer tentativa de mudar alguma coisa, mesmo que para melhor, esbarra numa muralha de conservadorismo" (SIMON, 2015, grifo nosso). A carta aberta do Cais Mauá de Todos elencou vários itens em contraposição ao que seria a "muralha do conservadorismo". Num deles, posiciona-se em relação à criação de PPPs para o projeto:

Uma "muralha de conservadorismo" se constrói por quem acredita que os românticos são contra a iniciativa privada. Pelo contrário, achamos que o instrumento PPP é bastante apropriado, desde que devidamente regulado pelo Estado em prol da cidade. A questão é que isso não está acontecendo: a regulação não existe, a iniciativa privada comanda a operaçáo, define o que quer à revelia da lei e modifica incessantemente o projeto buscando enxugar recursos. Que fique bem claro, queremos sim a revitalização dos armazéns e seu uso para comércio, restaurantes, serviço e cultura. $\mathrm{O}$ que não aceitamos é o argumento de que a desfiguração da área com um projeto mutilado é a única possibilidade. Esse discurso de "ou é isso ou é nada" não cola. (SIMON, 2015, grifo nosso)

Entendemos esse fenômeno de duas perspectivas distintas, porém complementares: da perspectiva da prática política dos movimentos organizados que contestam a revitalização do Cais Mauá; e do ponto de vista do conflito social inerente ao espaço fenômeno mais amplo do que qualquer movimento organizado. Como dito, estamos trabalhando com dois fenômenos distintos, mas absolutamente relacionados: um conflito social e um movimento organizado. Vimos que, de acordo com Lefebvre (2014), conflitos sociais podem ser encobertos por ideologias, ficando, assim, imperceptíveis, mesmo que reais. O conflito, nesse caso, é latente. Já o movimento organizado é perceptível, concreto e, portanto, atua em um plano distinto.

A partir da tipologia de planejamento urbano proposta por Souza (2002), o primeiro desses fenômenos - a prática política do movimento organizado - é entendido como um planejamento comunicativo/colaborativo, categoria teórica influenciada pelo filósofo Jürgen Habermas. Sua ênfase é na colaboração e na comunicação entre os atores, uma vez que seria possível, "dentro do contexto do agir comunicativo [,] chegar-se a acordos voluntários em nome da cooperação" (SOUZA, 2002, p. 150). Ou seja, não há uma ruptura, um conflito, mas a vontade de comunicaçáo e colaboração dos planejadores: "O compromisso com a ética do discurso que evite ao máximo o recurso à violência física é algo crucial de um ponto de vista que recuse estratégias autoritárias" (SOUZA, 2002, p. 150). Essa abordagem explica a intenção pacifista, não conflituosa e colaboracionista do movimento, quando, por exemplo, opta por náo ocupar o espaço e por não se contrapor a uma PPP. Isto é, o Movimento Cais Mauá de Todos troca um projeto pelo outro. Seu projeto alternativo náo é elaborado por uma diversidade de atores, nem mesmo pela comunidade. Ainda assim, é uma outra possibilidade que, de alguma maneira, confronta a transformação do espaço e a destruição do patrimônio histórico, ambiental e social. A abordagem do planejamento comunicativo/colaborativo, no entanto, ajuda-nos a compreender apenas o lado concreto das açóes dos movimentos organizados.

Já o segundo fenômeno salta aos olhos quando vemos o conflito sob um ângulo histórico e discursivo - um conflito que permeia a sociedade porto-alegrense desde muito antes do surgimento do projeto de revitalização do Cais Mauá, como fica claro na fala de um dos membros do movimento Cais Mauá de Todos: 
Sempre a nossa narrativa enquanto movimento social foi de enfatizar esse aspecto fazendo uma espécie de retrospectiva. Nós tivemos a tentativa de demolição do mercado público [...] depois nós tivemos a questão do próprio Gasômetro [...] então nós temos uma tradição de defesa da cidade em relação ao aspecto ambiental e ao aspecto urbano e uma participação muito grande da sociedade neste sentido, de se mobilizar para isso. Tivemos o próprio Parcão, que também na década de [19]40 teve uma ação forte. Então quando a gente inicia esse movimento, na verdade é um movimento que começa lá com a revisão do plano diretor de desenvolvimento urbano e ambiental de Porto Alegre em 2007 (VOLINO, 2016).

Percebemos nesse relato uma narrativa que evidencia a existência de conflitos recorrentes sobre o espaço urbano, bem como de manifestaçóes distintas de rechaços, oriundas de movimentos organizados da sociedade. Aqui, interessa-nos sublinhar a própria constituição do espaço como sendo inerentemente contraditória e conflituosa, mas que se torna de fato conflituosa a partir do momento que a oposição organizada de grupos e movimentos logra interromper o processo de transformação do espaço pela especulação imobiliária, o que não deixa de ser, de certo modo, a criação de espaços públicos. Em outros termos, o conflito é inerente ao espaço, mesmo que permaneça em um estado de latência (LUKES, 1993). Ele irrompe apenas com a mobilização organizada da sociedade, ainda que sem resultados e direçôes definidas.

Nesse caso, o conceito de planejamento e gestão urbanos críticos ajuda na compreensão (SOUZA, 2002). Essa abordagem parte de uma perspectiva autonomista, desenvolvida pelo autor tendo como referência o conceito de autonomia do filósofo Cornelius Castoriadis:

Assim como certos agentes modeladores do espaço correspondentes a fraçóes de classe e a grupos dominantes, como o grande capital industrial e imobiliário, elaboram suas geoestratégias de forma clara e, não raro, sofisticada, também a parcela majoritária da sociedade civil, que não pertence a nenhum grupo dirigente, precisa, sob um ângulo autonomista, qualificar-se e organizar-se para elaborar suas propostas e estratégias e lutar para pô-las em prática. Essa luta deverá combinar tanto pressóes sobre o Estado quanto açóes diretas (SOUZA, 2002, p. 178).

Essa abordagem questiona o planejamento que ignora os saberes locais e os modos de vida, "como se as aspiraçôes dos homens e mulheres concretos devessem ser definidas por outros que não eles mesmos". Entende que "o significado da participaçáo dos indivíduos no processo de planejamento não é o de uma participação destes em processos decisórios comandados e coordenados pelo Estado como instância de poder separada" (SOUZA, 2002, p. 180). O rechaço do Estado como uma instância separada é parte de um processo de desalienação (LEFEBVRE, 2014), no qual a produçáo do espaço deixa de ser resultado da vontade de um grupo que se sobrepóe a outros, passando a ser o processo mesmo de produçáo social, com seus conflitos e contradições visíveis, atuantes. Nesses processos, são os próprios conflitos que produzem o espaço, e não o projeto. 


\section{CONSIDERAÇÕES FINAIS}

Verificamos, a partir do que foi até aqui discutido, uma disputa clara pelo espaço urbano, precisamente por um espaço público, um lugar simbólico, de conexão com a natureza e com a história. De um lado, a ordem distante, representada não apenas pelo Estado, mas também por empresas internacionais, elites e mídia local; de outro, a ordem próxima, a comunidade e a vizinhança. O movimento Cais Mauá de Todos, via atividades que promoviam a cultura, o lúdico, a festa, o encontro e a troca, estimulou o crescimento desse sentimento de comunidade, ou seja, propiciou o fortalecimento da ordem próxima. Essas ações não poderiam acontecer em outro lugar que não no espaço público, onde a compreensão da tríade do espaço vivido-concebido-percebido pode ser realizada em sua plenitude.

Contraditoriamente, ao promover o lúdico, a festa e o encontro, promoveram também o conflito. Não no sentido de criação de conflitos inexistentes, mas no de desvelamento. O conflito deixa de ser latente (LUKES, 1993), passando a ser perceptível; ele sai à superfície, mas com um formato lúdico. Cumpre, assim, uma dupla função: de desalienação e de reapropriação do espaço por aqueles que nele vivem.

O GPU Cais Mauá, articulado pela ordem distante, aparece, nesse sentido, causando uma ruptura no entendimento da tríade proposta por Lefebvre; através do saber técnico e político, retificando o espaço público, privatizando-o, construindo-o por meio de símbolos e signos de distinção social, o GPU torna o espaço abstrato. Essa abstração, a partir de perspectivas em três dimensôes, de imagens de publicidade e propaganda que seduzem com a idealização de como será, futuramente, o empreendimento, busca criar um consenso em torno do projeto. Ela traz consigo, igualmente, uma falsa consciência.

Nesse sentido, o GPU não pode ser visto como uma ferramenta de planejamento urbano. É, antes de tudo, uma possibilidade, um arranjo para intervir no espaço urbano de maneira orientada para o mercado. Ele apresenta soluçóes e perspectivas algumas vezes falsas, sem possibilitar que a sociedade conheça realmente como será o projeto. Em certos casos, o GPU se transforma num empecilho à compreensão da cidade que está sendo projetada, um empecilho ao espaço urbano de todos. A impossibilidade de participação da população e de movimentos sociais vai além, uma vez que esse arranjo é fundamentado em uma PPP, em que os interesses privados sempre prevalecerão sobre o público, independentemente de qualquer regulamentação.

\section{REFERÊNCIAS}

ALTSHULER, A; LUBEROFF, D. Mega-projects: the changing politics of urban public investments. Harrisonburg: R. R. Donnelley, 2003.

CAIS Mauá. Viva o Centro. Portal PMPA, Porto Alegre, 2013. Disponível em: <http:// lproweb.procempa.com.br/pmpa/prefpoa/vivaocentro/default.php?p_secao=114>. Acesso em: 17 jun. 2013.

CAIS Mauá de todos. Fanpage Facebook. Disponível em <https://www.facebook.com/caismauadetodos>. Acesso em: 31 ago. 2015.

CARTA aberta à população de Porto Alegre: como queremos nosso Cais Mauá? (pelo Movimento Ocupa Cais Mauá). Sul 21, Porto Alegre, 27 nov. 2014. Disponível em: <http://

\begin{abstract}
Clarice Misoczky de Oliveira é graduada em Arquitetura e Urbanismo, mestre e doutoranda em Planejamento Urbano e Regional pela Universidade Federal do Rio Grande do Sul (UFRGS). E-mail: arq.clarice@gmail. com

Rafael Kruter Flores é graduado, mestre e doutor em Administração pela Universidade Federal do Rio Grande do Sul (UFRGS); Professor Adjunto na Escola de Administração e no Programa de Pós-Graduação em Administração da UFRGS.

E-mail: rafael.flores@ufrgs.br

Artigo recebido em 31 de agosto de 2015 e aprovado para publicação em 22 de agosto de 2016 .
\end{abstract}


www.sul21.com.br/jornal/carta-aberta-a-populacao-de-porto-alegre-como-queremosnosso-cais-maua-pelo-movimento-ocupa-cais-maua/>. Acesso em: 31 ago. 2015.

CONCESSIONÁRIA entrega projeto de revitalização do Cais Mauá. Notícias Portal PMPA, Porto Alegre, 12 set. 2011. Disponível em: <http://www2.portoalegre.rs.gov.br/ portal_pmpa_novo/default.php?p_noticia=145253\&CONCESSIONARIA+ENTREGA+PROJETO+DE+REVITALIZACAO+DO+CAIS+MAUA>. Acesso em 30 jul. 2013.

DEFENSORES de alternativa para Cais Mauá convocam novo ato festivo. Jornal Já, Porto Alegre, 22 maio 2015. Disponível em: <http://jornalja.com.br/defensores-de-alternativa-para-cais-maua-convocam-novo-ato-festivo/>. Acesso em: 31 ago. 2015.

FOGAÇA recebe projeto de revitalização do Cais Mauá. Notícias Portal PMPA, Porto Alegre, 6 maio 2009. Disponível em: <http://www2.portoalegre.rs.gov.br/portal_pmpa_novo/ default.php?p_noticia=106974\&FOGACA+RECEBE+PROJETO+DE+REVITALI$\mathrm{ZACAO}+\mathrm{DO}+\mathrm{CAIS}+\mathrm{MAUA} \geq$. Acesso em: 30 jul. 2013.

FRIEDMANN, J. The World City Hypothesis. Development and Change, 1986. In: BRENNER, N.; KEIL, R. (Ed.). The Global Cities Reader. Oxon: Routledge, 2010. p. 67-71.

HARVEY, D. A produção capitalista do espaço. São Paulo: Annablume, 2006.

Condição Pós-Moderna: Uma pesquisa sobre as origens da mudança cultural. São Paulo: Ediçóes Loyola, 2011.

HOFMEISTER, N. Grupo estuda viabilidade econômica de alternativa para Cais Mauá. Jornal Já, Porto Alegre, 20 abr. 2015. Disponível em: <http://jornalja.com.br/grupo-estuda-viabilidade-economica-de-alternativa-para-cais-maua/>. Acesso em: 31 ago. 2015.

INGALINA, P. Le projet urbain. Paris: Presses Universitaires de France, 2001.

LECROART, P.; PALISSE, J. P. Grands Projets Urbains em Europe: quels enseignements pour l'île-de-France. Les Cahiers de l'institut d'aménagement et d'urbanisme de la region d'Tle-de-France, Paris, n. 146, p. 5-27, mar. 2007.

LEFEBVRE, H. The production of space. Oxford: Blackwell, 1991. $O$ direito à cidade. São Paulo: Centauro, 2001. . A revolução urbana. Belo Horizonte: Ed. UFMG, 2008a. Espaço e política. Belo Horizonte: Ed. UFMG, 2008b. Critique of Everyday Life. London: Verso, 2014.

LOGAN, J. R.; MOLOTCH, H. L. The City as a Growth Machine. In: FAINSTEIN, S. S.; CAMPBELL, S. (Ed.). Readings in Urban Theory. Oxford: Blackwells, 1993. p. 291-337.

LUKES, S. Power: a radical view. New York: MacMillan, 1993.

MAENNIG, W. World Cup 2010: South African economic perspectives and policy challenges informed by the experience of Germany 2006. Hamburg: Universität Hamburg, 2009.

MARX, K. Capital. London: Penguin classics, 1990. v. 1.

MELO, I. Pontapé inicial: Novo cais até a Copa. Zero Hora, Porto Alegre, 23 nov. 2011, p. 4-5.

NOVAIS, P. et al. Grandes Projetos Urbanos: panorama da experiência brasileira. In: ENCONTRO NACIONAL DA ANPUR, 12., 2007, Belém. Anais... Belém: ANPUR, 2007. Disponível em: <http://unuhospedagem.com.br/revista/rbeur/index.php/anais/ article/view/2390/2363>. Acesso em: 15 mai. 2016.

O QUE é a defesa pública da alegria? Catarse, coletivo de comunicação, Porto Alegre, 5 out. 2012. Disponível em: <http://coletivocatarse.com.br/home/o-que-e-a-defesa-publicada-alegria/>. Acesso em: 21 ago. 2015.

OLIVEIRA, S. Retrospectiva dos protestos em Porto Alegre: 2013, o ano que não terminou. Sul 21, Porto Alegre, $25 \mathrm{dez}$. 2013. Disponível em: <http://www.sul21.com.br/jornal/ 
retrospectiva-2013-o-ano-que-nao-terminou/>. Acesso em: 23 ago. 2015.

REVITALIZAÇÃO do Cais Mauá entre as prioridades para a Copa de 2014. Notícias Portal PMPA, Porto Alegre, $11 \mathrm{dez}$. 2008. Disponível em: <http://www2.portoalegre.rs.gov. br/portal_pmpa_novo/default.php?p_noticia $=100631 \&$ REVITALIZACAO+DO+CAIS+MAUA+ENTRE+AS+PRIORIDADES+PARA+A+COPA+DE+2014>. Acesso em: 23 jul. 2013.

SERENATA Iluminada Cais Mauá. Evento Facebook, Porto Alegre, 2014. Disponível em: $<$ https://www.facebook.com/events/787293858026240/>. Acesso em: 31 ago. 2015.

SIMON, G. Rosane de Oliveira (ZH) faz ótimo artigo sobre a Revitalização do Cais Mauá. Blog Porto Imagem, Porto Alegre, 20 set. 2015. Disponível em: <https://portoimagem. wordpress.com/2015/09/20/rosane-de-oliveira-zh-faz-otimo-artigo-sobre-a-revitalizacao-do-cais-maua/>. Acesso em 10 jun. 2016.

SOUZA, M. L. Mudar a cidade: uma introdução crítica ao planejamento e à gestão urbanos. Rio de Janeiro: Bertrand Brasil, 2002.

VOLINO, J. Porto Alegre. Entrevistador: Rafael Kruter Flores. Brasil: Gravada em meio digital, 2016. 